\title{
Comparative Study between the Complications of Sleeve Gastrectomy versus the Complications of Gastric Bypass
}

\author{
Mohamed Fathy Sharaf, Eslam Taha Ghalwash, *Mohammed Ali Abdelaty Awad Elkelany \\ Departments of General Surgery, Faculty of Medicine, Al-Azhar University \\ *Corresponding Author: Mohammed Ali Abdelaty Awad Elkelany, E-mail: Mohammedkelany1985@gmail.com
}

\begin{abstract}
Background: obesity means having too much body fat. Causes of obesity includes: diet, sugar overload, genetics, insufficient sleep, social determinants, environment, and stress. Complications of obesity includes: type II diabetes mellitus, heart diseases, metabolic syndrome, hyperlipidemia, respiratory diseases, male sexual dysfunction, neurological diseases, gastrointestinal diseases, rheumatic diseases, urological diseases, psychological abnormalities, trauma, pancreatic diseases, gall bladder diseases, diverticulitis and hernia. Sleeve gastrectomy is an excellent procedure for management of morbid obesity. Complications of Sleeve gastrectomy includes: Hemorrhage, leakage, nutritional deficiencies, ineffective EWL and weight regain, cholelithiasis, stenosis, gastroesophageal reflux disease GERD and hiatus hernia, gastric torsion, gastro-bronchial fistula and venous thrombosis. Complications with Roux-en-Y Gastric Bypass includes: Hemorrhage, leakage, nutritional deficiencies, ineffective excess weight loss EWL and weight regain, trocar site hernia, cholelithiasis, dumping syndrome, Internal hernia, obstruction of the biliopancreatic limb, intussusceptions volvulous, gastrogastric fistula, marginal ulceration and gastrojejunostomy anastomotic stricture.
\end{abstract}

Aim: To compare complications associated with Sleeve Gastrectomy versus complications associated with open or laparoscopic Gastric Bypass and its effects on patients' life and to know which procedure is better.

Patients and Methods: group (A): includes 15 cases underwent sleeve gastrectomy. With inclusion criteria of obese patients with body mass index (BMI) $\geq 40 \mathrm{~kg} / \mathrm{m} 2$ or BMI $\geq 35 \mathrm{~kg} / \mathrm{m} 2$ with associated co morbidity (hypertension, Diabetes mellitus, hyperlipidemia, arthritis, cardiac diseases, etc.) and exclusion criteria of patients with previous bariatric surgery, previous upper gastrointestinal surgery, hiatus hernias, heavy sweet eaters, drug and/or alcohol addiction, psychiatric disorders and patients $>60$ years old or $<18$ years old were excluded and group (B): includes 15 cases underwent gastric bypass with inclusion criteria of obese patients with body mass index (BMI) $>40 \mathrm{~kg} / \mathrm{m} 2$ or BMI $>35 \mathrm{~kg} / \mathrm{m} 2$ with associated comorbidity (hypertension, Diabetes mellitus, hyperlipidemia, arthritis, cardiac diseases, etc.) and heavy sweet eaters and exclusion criteria of patients with previous bariatric surgery, previous upper gastrointestinal surgery apart from laparoscopic cholecystectomy. Patients with hiatus hernias, drug and/or alcohol addiction, psychiatric disorders and patients $>60$ years old or $<18$ years old were excluded.

Results: three complications developed with sleeve gastrectomy $20 \%$ as follows 1 case of hemorrhage $6.6 \%$, 1 case of leakage $66 \%$ and one case of gall bladder stones while gastric bypass complications resembles 2 cases $13.3 \%$ as follows: 1 case of deep venous thrombosis $6.6 \%$ and one case of gall bladder stones $6.6 \%$.

Conclusion: obesity is a common disease affecting more than 300 million adults worldwide. It is defined as a body mass index greater than $30 \mathrm{~kg} / \mathrm{m}^{2}$. The laparoscopic sleeve gastrectomy was adopted as a primary procedure and over time it has become the most popular bariatric operation worldwide and it is effective for weight loss and results in improvement and even resolution of co-morbidities like type 2 diabetes. Laparoscopic gastric bypass surgery is another safe and simple surgical intervention for treating morbid obesity and diabetes mellitus and is now being performed more frequently

Recommendations: both sleeve gastrectomy SG and roux-en-y gastric bypass RYGB are safe, short, simple and effective bariatric operations. Our study showed Roux-en-y gastric bypass has less complication than Sleeve gastrectomy. Further prospective studies have to be applied to a larger number of patients for longer periods of follow up are needed.

Keywords: Obesity- Sleeve Gastrectomy- Roux-En-Y Gastric Bypass.

\section{INTRODUCTION}

Obesity means having too much body fat. It is different from being overweight, which means weighing too much. The weight may come from muscle, bone, fat, and/or body water. Both terms mean that a person's weight is greater than what's considered healthy for his or her height ${ }^{(\mathbf{1})}$.

Being obese increases risk of diabetes, heart disease, stroke, arthritis, and some cancers. If you are obese, losing even 5 to 10 percent of your weight 
can delay or prevent some of these diseases. For example, that means losing 10 to 20 pounds if you weigh 200 pounds ${ }^{(\mathbf{1})}$.

Sleeve gastrectomy is an excellent procedure for the surgical management of morbid obesity. Expected weight loss at 6 and 12 months averages $49 \%$ and $56 \%$, respectively. Improvement in comorbidities of obesity, such as hypertension and diabetes mellitus, has been reported to occur in the majority of patients with resolution in $60-100 \%{ }^{(2)}$.

The complications of sleeve gastrectomy includes: hemorrhage, leak, deep vein thrombosis, pulmonary embolus and abscess stricture, nutrient deficiency, Gastro-esophageal reflux disease (GERD) and gastric sleeve dilatation. The risk of postoperative bleeding has been reported to be between $1 \%$ and $6 \%$ after laparoscopic sleeve gastrectomy (LSG). The source of bleeding can be intra- or extra luminal. Intra luminal bleeding from the staple line usually presents with an upper gastrointestinal bleed. Extra luminal bleeding include the gastric staple line, spleen, liver or abdominal wall at the sites of trocar entry ${ }^{(3)}$.

Laparoscopic Gastric Bypass is a mixed restrictive and malabsorptive bariatric surgery. Complications including marginal ulcers, chronic alkaline reflux, Barrett's esophagus, anastomosis leakage, and stenosis requiring revisional surgery made it less popular; however, it also has some advantages, such as one less anastomosis, shorter operative time, lower risk of anastomotic leakage and internal herniation, shorter learning curve, and the ease of reversibility. ${ }^{(4)}$

\section{AIM OF THE WORK}

To compare complications associated with Sleeve Gastrectomy either open or laparoscopic versus complications associated with open or laparoscopic Gastric Bypass and its effects on patients' life and to know which procedure is better as regard avoiding complications as possible.

\section{PATIENTS AND METHODS}

This comparative prospective study was conducted in Al- Hoseen and Said Galal University hospitals.

The study groups were selected from the Surgery department inpatients, the study was on patients suffering from morbid obesity. They were diagnosed as morbidly obese according to BMI of more than $40 \mathrm{~kg} / \mathrm{m}^{2}$ with or without obesity related comorbidities or with BMI of more than $35 \mathrm{Kg} / \mathrm{m}^{2}$ with obesity related comorbidities and had suffering at least 5 years of morbid obesity and all of them had failed trials of conservative management.

\section{Target population:}

Group (A): includes 15 cases underwent sleeve gastrectomy.

\section{Inclusion criteria:}

Included obese patients with body mass index $(\mathbf{B M I}) \geq 40 \mathrm{~kg} / \mathrm{m}^{2}$ or $\mathbf{B M I} \geq 35 \mathrm{~kg} / \mathrm{m}^{2}$ with associated comorbidity (hypertension, Diabetes mellitus, hyperlipidemia, arthritis, cardiac diseases, etc.).

\section{Exclusion criteria:}

Included patients with previous bariatric surgery, previous upper gastrointestinal surgery (open or laparoscopic) apart from laparoscopic cholecystectomy. Patients with hiatus hernias, heavy sweet eaters, drug and/or alcohol addiction, psychiatric disorders and patients $>60$ years old or $<18$ years old were excluded.

Group (B): includes 15 cases underwent gastric bypass.

\section{Inclusion criteria:}

Obese patients with body mass index (BMI) $>40 \mathrm{~kg} / \mathrm{m} 2$ or $\mathrm{BMI}>35 \mathrm{~kg} / \mathrm{m} 2$ with associated comorbidity (hypertension, Diabetes mellitus, hyperlipidemia, arthritis, cardiac diseases, etc.) and heavy sweet eaters.

\section{Exclusion criteria:}

Included patients with previous bariatric surgery, previous upper gastrointestinal surgery (open or laparoscopic) apart from laparoscopic cholecystectomy. Patients with hiatus hernias, drug and/or alcohol addiction, psychiatric disorders and patients $>60$ years old or $<18$ years old were excluded.

\section{All patients were subjected basically to the following:}

\section{Written informed consent:}

It was obtained from each patient, including explanation of the procedure, description of the technique, the possible side effects and outcome which may be favorable or not.

2. All patients had failed trials of conservative weight reduction in the form of life style 
changes (increase exercise, medically supervised diet control) and drug therapy to decrease weight.

3. Full history taking with particular attention to:
a) Age of patients.
b) Duration of obesity.
c) History of medications, steroid treatment, hormonal therapy.
d) History of previous diseases (diabetes mellitus, hypertension, bronchial asthma, obstructive sleep apnea, ischemic heart disease, peripheral vascular disease, liver disease, osteoarthritis and degenerative joint disease.
e) Past history of surgical operations especially abdominal operations or history of blood transfusion.
f) Nutritional counseling.
g) Psychiatric counseling.
h) History of smoking or drug abuse.

4. Full clinical examination including pattern of obesity and weight, BMI measurement.

5. Preoperative investigations in the form of:

i. Complete blood count. ii. Lipid profile, blood cholesterol and triglyceride assay.

iii. Liver and kidney functions tests.

iv. Blood glucose level.

v. Hormonal assay in selected patients (Cushing's disease or myxedema).

vi. Pulmonary function tests.

vii. Chest $\mathrm{x}$-ray.

viii. Electrocardiogram.

ix. Abdominal ultrasound.

\section{RESULTS}

This combined retrospective and prospective comparative study was done at Alhosen and Said Galal hospitals, Al-Azhar University. It included 30 obese patients, divided into two groups; group A: sleeve gastrectomy (SG) and group B: gastric bypass (RYGB). Group (A) included 15 cases, and group (B) included 15 cases as well.

Table 1: summarizes the demographic data of the patients, who underwent SG included in the study, while table 2: summarizes the demographic data of the patients who underwent RYGB.

Table 1: Demographic and clinical data of patients for group A

\begin{tabular}{c|c|c|c|c|c|c}
\hline \hline Number of SG cases & Females & Males & $\begin{array}{c}\text { Range of } \\
\text { age (year) }\end{array}$ & $\begin{array}{c}\text { Age } \\
(\mathbf{m e a n})\end{array}$ & $\begin{array}{c}\text { BMI range } \\
\left(\mathbf{k g} / \mathbf{m}^{\mathbf{2}}\right)\end{array}$ & Co-morbidities \\
\hline \hline 15 & 9 & 6 & $18-55$ & 38 & $35-55$ & 3 (2diabetics \& 1hypertensiv) \\
\hline \hline
\end{tabular}

Table 2: Demographic and clinical data of patients for group B

\begin{tabular}{c|c|c|c|c|c|c}
\hline $\begin{array}{c}\text { Number of } \\
\text { RYGB cases }\end{array}$ & Females & Males & $\begin{array}{c}\text { Range of } \\
\text { age (year) }\end{array}$ & $\begin{array}{c}\text { Age } \\
(\mathbf{m e a n})\end{array}$ & $\begin{array}{c}\text { BMI range } \\
\left(\mathbf{k g} / \mathbf{m}^{\mathbf{2}}\right)\end{array}$ & Co-morbidities \\
\hline \hline 15 & 8 & 7 & $18-53$ & 34.68 & $35.45-74.74$ & $\begin{array}{c}8(2 \text { diabetics, 2 hypertensive, } 2 \\
\text { osteoarthritis, 1 gall stone, and 1 } \\
\text { elephantiasis })\end{array}$ \\
\hline \hline
\end{tabular}

\section{Group A: sleeve gastrectomy group:}

Thirteen patients underwent LSG and the other 2 underwent open SG and 1 patient converted from LSG to open SG. Three complications (20\%) were encountered in 3 patients from 15 patients who underwent SG, 2 of which were early including one case of intraoperative hemorrhage
(6.6\%) and one case of gastric leakage $(\mathbf{6 . 6 \%})$ in the first postoperative day, while the last one was the development of gall bladder stones (6.6\%) detected one year after surgery.

Table 3: summarizes the different types of complications that occurred in the SG group. 
Table 3: Complications of SG group

\begin{tabular}{l|l|c}
\hline \hline Total number of SG cases & 15 \\
\hline \hline \multirow{4}{*}{ Complications } & Total & $3(20 \%)$ \\
\cline { 2 - 3 } & Hemorrhage & $1(6.6 \%)$ \\
\cline { 2 - 3 } & Staple line leakage & $1(6.6 \%)$ \\
\cline { 2 - 3 } & Gall bladder stones & $1(6.6 \%)$ \\
\hline \hline
\end{tabular}

One patient $(\mathbf{6 . 6 \%})$ developed gall bladder stones 12 months after surgery. Her BMI was $\mathbf{5 0}$ $\mathrm{kg} / \mathrm{m}^{2}$. The diagnosis was made by abdominal ultrasound during the follow up period. The patient was asymptomatic and not diabetic Laparoscopic cholecystectomy was done for her.

The laboratory results done during the follow up period to detect the nutritional deficiencies didn't reveal any abnormality. No complications regarding GERD, and gastric obstruction occurred. All patients achieved their expected weight loss (EWL) in their appropriate time with no incidence of weight loss failure. No mortality occurred among this group.

\section{group:}

Group B: Roux-en-Y Gastric Bypass

Twelve patients underwent LRYGB and the other 3 open RYGB. Two complications $\mathbf{( 1 3 . 3 \% )}$ ) were encountered in 2 patients. Both were late in the form of gallbladder stones $(\mathbf{6 . 6 \%})$ and deep venous thrombosis (DVT) (6.6\%). Both were detected $\mathbf{6}$ months after surgery.

One patient $(\mathbf{6 . 6 \%})$ developed gall bladder stones 6 months after surgery. Her BMI was $\mathbf{4 4}$ $\mathrm{kg} / \mathrm{m}^{2}$. The patient was asymptomatic and not diabetic but hypertensive. The diagnosis was made by abdominal ultrasound during the follow up period. Laparoscopic cholecystectomy was done for her.

The other patient (6.6\%) developed DVT6 months after surgery. Her BMI was $\mathbf{4 4} \mathrm{kg} / \mathrm{m}^{2}$. The patient complained of pain and swelling in the calf muscle area and the examination revealed, tender swollen calf muscle of the left leg. The diagnosis was confirmed by venous duplex. The patient started therapeutic dose of anticoagulant.

Table 4: summarizes the different types of complications that occurred in RYGB group.

Table 4: Complications of RYGB group

\begin{tabular}{l|l|l}
\hline \hline \multicolumn{2}{l|}{ Total number of RYGB cases } & \multicolumn{1}{c}{$\mathbf{1 5}$} \\
\hline \hline \multirow{3}{*}{ Complications } & Total & $2(13.3 \%)$ \\
\cline { 2 - 3 } & DVT & $1(6.6 \%)$ \\
\cline { 2 - 3 } & Gall bladder stones & $1(6.6 \%)$ \\
\hline \hline
\end{tabular}

Table 5: Incidence of complications in both groups

\begin{tabular}{l|c|c|c}
\hline \hline \multicolumn{1}{c|}{ Complications } & $\begin{array}{c}\text { SG } \\
\text { group }\end{array}$ & $\begin{array}{c}\text { RYGB } \\
\text { group }\end{array}$ & P value \\
\hline \hline Total & $3(20 \%)$ & $2(12 \%)$ & 1.000 \\
\hline Hemorrhage & $1(6.6 \%)$ & 0 & 1.000 \\
\hline Leakage & $1(6.6 \%)$ & 0 & 1.000 \\
\hline Gall bladder stone & $1(6.6 \%)$ & $1(6.6 \%)$ & 0.470 \\
\hline DVT & 0 & $1(6.6 \%)$ & 1.000 \\
\hline \hline
\end{tabular}

\section{DISCUSSION}

Kular et al. ${ }^{(5)}$ found that The LSG group had a greater percentage of complications $\mathbf{( 4 6 \% )}$ than the RYGB group (25.6\%) in their study. In our study we had a greater percentage of complications among SG group (20\%) than RYGB (13.3\%). which goes hand in hand with the international results. However we had lower percentage of total complications compared to kular and colleagues ${ }^{(5)}$.

Table 6, 7 and 8 summarizes the incidence of complications after SG and RYGB respectively among different studies as well as ours.

Table 6: Incidence of complications among SG in different studies as well as ours

\begin{tabular}{l|c|c}
\hline \multicolumn{1}{c|}{ Study } & Number of Patients & Complication rate \\
\hline \hline Cottam et al. ${ }^{(\mathbf{( 6 )}}$ 2006 & 126 & $14 \%$ \\
\hline Hamoui et al.2006 & 118 & $15 \%$ \\
\hline Frezza et al. 2007 & 53 & $9.4 \%$ \\
\hline Triantafyllidis et al.2011 & 85 & $8 \%$ \\
\hline Mittermair et al. 2013 & 153 & $46 \%$ \\
\hline Kular et al.2014 & 118 & $1.6 \%$ \\
\hline Lee et al. ${ }^{(7)}$ 2015 & 519 & $20 \%$ \\
\hline Our study & 15 & $2.9 \%$ \\
\hline \hline
\end{tabular}


Table 7: Incidence of complications among RYGB in different studies as well as ours

\begin{tabular}{l|c|c}
\hline \hline \multicolumn{1}{c|}{ Study } & Number of Patients & Complication rate \\
\hline \hline Chevallier et al. 2008 & 451 & $11 \%$ \\
\hline Lee et al. 2012 & 175 & $11.3 \%$ \\
\hline Noun et al. 2012 & 923 & $6 \%$ \\
\hline Musella et al.2014 & 974 & $5.9 \%$ \\
\hline Kular. et al. ${ }^{(5)} \mathbf{2 0 1 4}$ & 1054 & $1.9 \%$ \\
\hline Lee WJ et al.2015 & 519 & $13.3 \%$ \\
\hline Our study & 15 & \\
\hline \hline
\end{tabular}

Table 8: Comparison of complications between SG and RYGB in different series

\begin{tabular}{l|c|c|c|c}
\hline \multicolumn{1}{c|}{ Study } & $\begin{array}{c}\text { Total number of } \\
\text { patients } \\
(\text { LSG/RYGB) }\end{array}$ & $\begin{array}{c}\text { Total number of } \\
\text { complications } \\
(\%)\end{array}$ & $\begin{array}{c}\text { Number of } \\
\text { complications } \\
\text { in SG }(\%)\end{array}$ & $\begin{array}{c}\text { Number of } \\
\text { complications in } \\
\text { RYGB (\%) }\end{array}$ \\
\hline \hline Lee et al. $2015^{(7)}$ & $1038(519 / 519)$ & $87(8.4 \%)$ & $38(7.3 \%)$ & $49(4.7 \%)$ \\
\hline Our study & $30(15 / 15)$ & $5(16.6 \%)$ & $3(10 \%)$ & $2(6.6 \%)$ \\
\hline \hline
\end{tabular}

Leakage:

In our study there was one case $(\mathbf{6 . 6 \%})$ of early gastric leak (first postoperative day) at the gastroesophageal junction confirmed by the routine gastrograffin meal, and it was successfully managed by surgical repair and drainage. Over sewing the staple line is not followed routinely in our practice.

Table (9) summarizes the percentage of the leakage among the different studies in comparison to ours. While Musella and colleagues had a total leakage of $\mathbf{1 0 \%}$ divided as $\mathbf{0 . 2 \%}$ from the excluded stomach, $0.5 \%$ from the gastric tube and $\mathbf{0 . 3 \%}$ from the GJ anastomosis. ${ }^{(\mathbf{8}) \text {. There was no }}$ anastomotic leakage developed among the RYGB patients in our study.

Table 9: Leakage in different studies as well as ours

\begin{tabular}{l|c|c}
\hline \hline \multicolumn{1}{c|}{ Study } & $\begin{array}{c}\text { Number } \\
\text { of patients }\end{array}$ & Leakage (\%) \\
\hline \hline Frezza et al. 2007 & 53 & $2(3.7 \%)$ \\
\hline Lalor et al.2008 & 148 & $1(0.7 \%)$ \\
\hline $\begin{array}{l}\text { Mittermair et al. } \\
\text { 2013 }\end{array}$ & 153 & $3(1.9 \%)$ \\
\hline Kular et al.2014 & 284 & $0(0 \%)$ \\
\hline Lee et al.2015 & 519 & $6(1.2 \%)$ \\
\hline Noun et al.2012 & 1000 & $5(0.5 \%)$ \\
\hline Musella et al. 2014 & 974 & $7(0.7 \%)$ \\
\hline Our study & 30 & $1(3.3 \%)$ \\
\hline \hline
\end{tabular}

\section{Hemorrhage:}

Kular and colleagues had intraoperative bleeding of $3.3 \%$ in LSG, while in RYGB achieved a much lower rate of $\mathbf{0 . 9 8 \%}{ }^{(5)}$

There was one case $\mathbf{( 3 . 3 \% )}$ of intraoperative bleeding during the division of the short gastric vessels and was managed as described above, in SG group in our study, However, in the RYGB group bleeding did not occur. This denotes that the incidence of bleeding in SG group is higher than that in RYGB group and that is consistent with other international publications.

Table 10: The incidence of bleeding in different studies as well as ours

\begin{tabular}{l|c|c}
\hline \multicolumn{1}{c|}{ Study } & $\begin{array}{c}\text { Number } \\
\text { of patients }\end{array}$ & Bleeding (\%) \\
\hline \hline Frezza et al. 2007 & 53 & $1(1.8 \%)$ \\
\hline Lalor et al. 2008 & 148 & $1(0.7 \%)$ \\
\hline $\begin{array}{l}\text { Mittermair et al. } \\
\text { 2013 }\end{array}$ & 153 & $5(3.3 \%)$ \\
\hline Kular et al. 2014 & 118 & $4(3.3 \%)$ \\
\hline Lee et al. 2015 & 519 & $1(0.2 \%)$ \\
\hline Our study & 30 & $1(3.3 \%)$ \\
\hline \hline
\end{tabular}

\section{Cholelithiasis:}

The incidence of cholelithiasis and choledocholithiasis is quite high in those who underwent LRYGB compared to LSG group; at present thought, LRYGB seems to be associated with increased risk of cholelithiasis but due to less 
number of cases, it is difficult to compare and maybe long-term follow-up and more number of procedures will further clarify the situation. In SG group we had one female patient (6.6\%) with BMI $50 \mathrm{~kg} / \mathrm{m}^{2}$ developed asymptomatic gall bladder stones one year after surgery.

Diagnosis was achieved by abdominal ultrasound during the follow up period. Laparoscopic cholecystectomy was done. In RYGB group we had also one patient $(\mathbf{6 . 6 \%})$ that developed gall bladder stones 6 months after surgery. Her BMI was $44 \mathrm{~kg} / \mathrm{m}^{2}$. The patient was asymptomatic and was not diabetic but was hypertensive. The diagnosis was made by abdominal ultrasound during the follow up period. Laparoscopic cholecystectomy was done. Table (11) demonstrates cholilithiasis after SG in comparison to RYGB in different studies as well as ours.

Table 11: Cholelithiasis in different studies compared to ours

\begin{tabular}{l|c}
\hline \hline \multicolumn{1}{c|}{ Study } & $\begin{array}{c}\text { Percentage of gall stone } \\
\text { formation }\end{array}$ \\
\hline \hline Kular et al. 2014 & $10.5 \%$ \\
\hline Mishra et al. 2016 & $8.42 \%$ \\
\hline Our study & $6.6 \%$ \\
\hline \hline
\end{tabular}

Deep venous thrombosis (DVT):

In our study one patient (3.3\%) developed DVT 6 months after surgery. Her BMI was 44 $\mathrm{kg} / \mathrm{m}^{2}$. The patient complained of pain and swelling in the calf muscle area and the examination revealed tender and swollen calf muscle. The diagnosis was confirmed by venous duplex. The patient started therapeutic dose of anticoagulant.

Table 12: Deep venous thrombosis among different studies as well as ours

\begin{tabular}{l|c|c}
\hline \multicolumn{1}{c|}{ Study } & $\begin{array}{c}\text { Number of } \\
\text { patient }\end{array}$ & $\begin{array}{c}\text { Complication } \\
\text { rate }\end{array}$ \\
\hline \hline Kular et al. 2014 & 1054 & $0(0 \%)$ \\
\hline $\begin{array}{l}\text { Musella } \text { et al. } \\
\mathbf{2 0 1 4}\end{array}$ & 974 & $0(0 \%)$ \\
\hline Noun et al. 2012 & 923 & $1(0.10)$ \\
\hline Our study & 30 & $1(3.3 \%)$ \\
\hline \hline
\end{tabular}

\section{CONCLUSION}

- Obesity is a worldwide epidemic accompanied with high rate of morbidity and mortality.
- Sleeve gastrectomy and Roux-en-y gastric bypass are both safe and effective procedure for the surgical management of morbid obesity.

- Sleeve gastrectomy complications include leakage, bleeding, stenosis, GERD, Cholelithiasis, nutritional deficiency, DVT, dumping; and failure of weight loss.

- Incidence of complications for SG is 0-24\%; and up to $46 \%$ in some studies, with a mortality rate of $0.39 \%$.Regarding RYGB highest overall complication rate was 9\% among all enrolled studies with mortality rate of $0.0 \%-0.18 \%$.

- Bleeding and leakage are the most common and most serious complication in both procedures.

\section{Recommendations}

- Both SG and RYGB are safe, short, simple and effective bariatric operations.

- Our study showed Roux-en-y gastric bypass has less complications than Sleeve gastrectomy.

- Further prospective studies have to be applied to a larger number of patients for longer periods of follow up are needed.

Many precautions should be done to prevent complications after both procedures:

\section{Leakage prevention by:}

Gentle handling of devices and staplers, avoiding distal stenosis, sustaining compression on the stable device before firing to washout fluids from the tissues and routine use of methylene blue test during surgery for detection of leaks.

\section{Hemorrhage prevention by:}

Reinforcement of stable line by oversewing with non-absorbable sutures ,applying fibrin sealant, incorporating buttressing materials or oversewing the bare stable line with sero-serosal layer.

\section{DVT prevention by:}

Perioperative subcutaneous heparin administration ,use of sequential compression devices on the legs or pump on the feet.

\section{CONFLICTS OF INTEREST}

There are no conflicts of interest. 


\section{REFERENCES}

1. Ding SA, Simonson DC and Wewalka $M$ et al. (2015): Adjustable gastric band surgery or medical management in patients with type 2diabetes: a randomized clinical trial. J ClinEndocrinol Metab., 2546-2556.

2. Colquitt JL, Pickett $\mathrm{K}$ and Loveman $\mathrm{E}$ et al. (2014): Surgery for weight loss in adults. https://www.ncbi.nlm.nih.gov/pubmed/2510 5982.

3. Angrisani L, Sanovino $P$ and, Formisano G et al. (2015): Bariatric surgery worldwide 2013. Obesity Surgery, 25:1822-32.

4. Mahawar KK, Carr W, and Balupuri S et al. (2014): Controversy surrounding 'mini' gastric bypass," Obesity Surgery, 24: (2):324-333.

5. Kular KS, Manshanda $N$, Rutledge $R$ (2014): A 6-year experience with 1,054 mini-gastric bypass-first study from indian subcontinent. Obesity Surgery:55:2414301435.
6. Kaur J (2014): A comprehensive review on metabolicsyndrome. https://www.hindawi.c om/journals/crp/2014/943162/

7. Cottam D, Qureshi FG, Mattar SG et al. (2006): Laparoscopic sleeve gastrectomy as an initial weight-loss procedure for highrisk patients with morbid obesity. Surg Endosc., 20(6):859-863.

8. Lee WJ, Han ML, and Ser KH et al. (2015): Laparoscopic Nissen Fundoplication with Gastric Plication as a Potential Treatment of Morbidly Obese Patients with GERD, First Experience and Results.https://www.ncbi.nlm.nih.gov/pubm ed/24610517

9. Musella M, Sousa A, Greco F et al. (2014): The laparoscopic mini-gastric bypass: the Italian experience: outcomes from 974 consecutive cases in a multicenter review. Surgery endoscopic, 28:156163. 